\title{
Alleviating the Effects of Chronic Disease in the Workplace: Opportunities for Intentional Change Theory
}

\author{
Loren R. Dyck \\ University of La Verne \\ Kathi J. Lovelace \\ Menlo College
}

Chronic disease is a national problem that has reached epidemic proportions with serious implications for the workplace. Essentially, the same set of individual health behavior change models have been applied to the treatment of chronic disease despite their inconsistent effectiveness. We examine the potential of Intentional Change Theory (ICT) to improve chronic disease outcomes and thereby contribute a fresh perspective on health behavior change. We review ICT and compare it with five existing theories of individual health behavior change. Our contribution is to articulate the value that ICT can bring to alleviating the effects of chronic disease in the workplace.

\section{INTRODUCTION}

According to the U.S. Centers for Disease Control and Prevention (2016) chronic disease such as obesity, diabetes, and cardiovascular disease are national problems that have reached epidemic proportions. To illustrate, a national survey of adults in the United States found that the age-adjusted prevalence of obesity in 2013-2014 was 35.0\% among men and 40.4\% among women (Flegal et al., 2016). In addition, 30.2 million (12.2\%) adults have diabetes, a disease in which the body does not produce or properly use insulin (CDC, 2017). Cardiovascular disease affects more than 85 million or over a third of U.S. adults (Mozaffarian et al., 2016). This disease includes high blood pressure, coronary heart disease, heart failure, and stroke. In fact, a recent RAND report found that $60 \%$ of Americans have at least one chronic disease and the costs associated with these diseases are not only financial but also physical and cognitive (Buttorff et al., 2017). It follows that chronic disease affects employee well-being and performance and is an increasingly important topic within organizational settings.

In many cases chronic diseases can be treated successfully with health behavior changes. For example, diabetes, despite serious complications and premature death "can be treated and managed by healthful eating, regular physical activity, and medications to lower blood glucose levels" (CDC, 2014, p. 4). Furthermore, managing health behavior change through organizational wellness programming has been shown to improve cardiovascular health (Carnethon et al., 2009) and help employees quit smoking, manage weight, and reduce stress, all of which are contributors to chronic disease (Goetzel \& Ozminkowski, 2008). In addition, Parks and Steelman's (2008) meta-analysis on the effectiveness of 
organizational wellness programs found a positive effect on decreased absenteeism and increased job satisfaction indicating that focusing on employee health benefits both the individual and the company.

Therefore, in this paper we aim to contribute to organizational psychology by offering Intentional Change Theory (ICT) as a theory-based change model that can be applied to health behavior change and wellness programming for managing and reducing chronic disease. ICT addresses the obstacles to an individual's healthy living by focusing on the whole person (Boyatzis \& McLeod, 2001) not just the disease; relating current self-care activities to a future healthy self-image; working with the strengths of the individual seeking change to connect to his or her ideal self; and empowering the individual to selfmanage. We contend that both the theoretical foundations and practical applications of ICT make it a valuable model for addressing chronic disease at work.

To better understand the potential contributions of ICT in managing chronic disease, we first introduce ICT and review its contributions to reducing chronic disease. We then present five models that are commonly cited for explaining how individual factors affect preventative health behavior choices. These models include the Transtheoretical Model (Prochaska \& DiClemente, 1982), Theory of Reasoned Action (Ajzen \& Fishbein, 1980; Fishbein \& Ajzen, 1975), Theory of Planned Behavior (Ajzen \& Fishbein, 1980; Fishbein \& Ajzen, 1975), Critical Care Model (Wagner, 1998), and the Health Belief Model (Rosenstock, 1974).

Our goal is to compare and contrast ICT with existing health behavior change models to demonstrate the ways in which ICT contributes to health behavior change and to show how these existing health behavior change models compete with, support, or have comparable elements to ICT. We suggest that ICT offers a new perspective on health behavior change that supplements and extends existing models which can be effectively applied to the workplace.

\section{INTENTIONAL CHANGE THEORY}

ICT, as shown in Figure 1, is a self-directed journey to personal change and learning. This model is an enhancement of earlier models (Boyatzis, 1999; Boyatzis \& Kolb, 1969; Kolb, 1971; Kolb \& Boyatzis, 1970a, 1970b; Kolb et al., 1968). ICT posits that one makes a mindful and willful decision to move towards one's ideal self as the purpose of change (Carr, 2004; Robbins et al., 1999). It involves an approach to personal change driven by the vision of a meaningful future, i.e. attraction to a future state. ICT is an iterative model that starts with the first of five Discoveries. A "Discovery" is a moment of learning something new about ourselves that is a discontinuity in the process of our self-understanding and a shock that requires our immediate attention to overcome it (Boyatzis, 2001). The five Discoveries include 1) finding one's ideal self, 2) determining one's real self, 3) developing a learning agenda, 4) experimenting and practicing new behaviors, and 5) developing trusting relationships. We present each of the Discoveries and their respective potential application to managing chronic disease.

\section{Discovery \#1: The Ideal Self}

The purpose of the ICT model is not change itself but rather moving toward the individual's ideal or desired end result. To illustrate this point, early writings by William James (1890/1950, p. 501) foreshadow subsequent research on imagining our preferred futures: "An anticipatory image, then, of the sensorial consequences of a movement, plus (on certain occasions) the fiat that these consequences shall become actual, is the only psychic state which introspection lets us discern as the forerunner of our voluntary acts." As illustrated in this quote, intentionality is important to the individual change process as adults change themselves and learn what they want to learn (Boyatzis, 2001). Individuals need to know the reason for changing their behavior before they change, and that reason must be personally compelling. This is especially true for patients with chronic illness as they are the primary healers of their own disease (Bartlett, 1986; de Weerdt et al., 1989a). 
FIGURE 1

BOYATZIS' INTENTIONAL CHANGE THEORY (BOYATZIS, 2001)

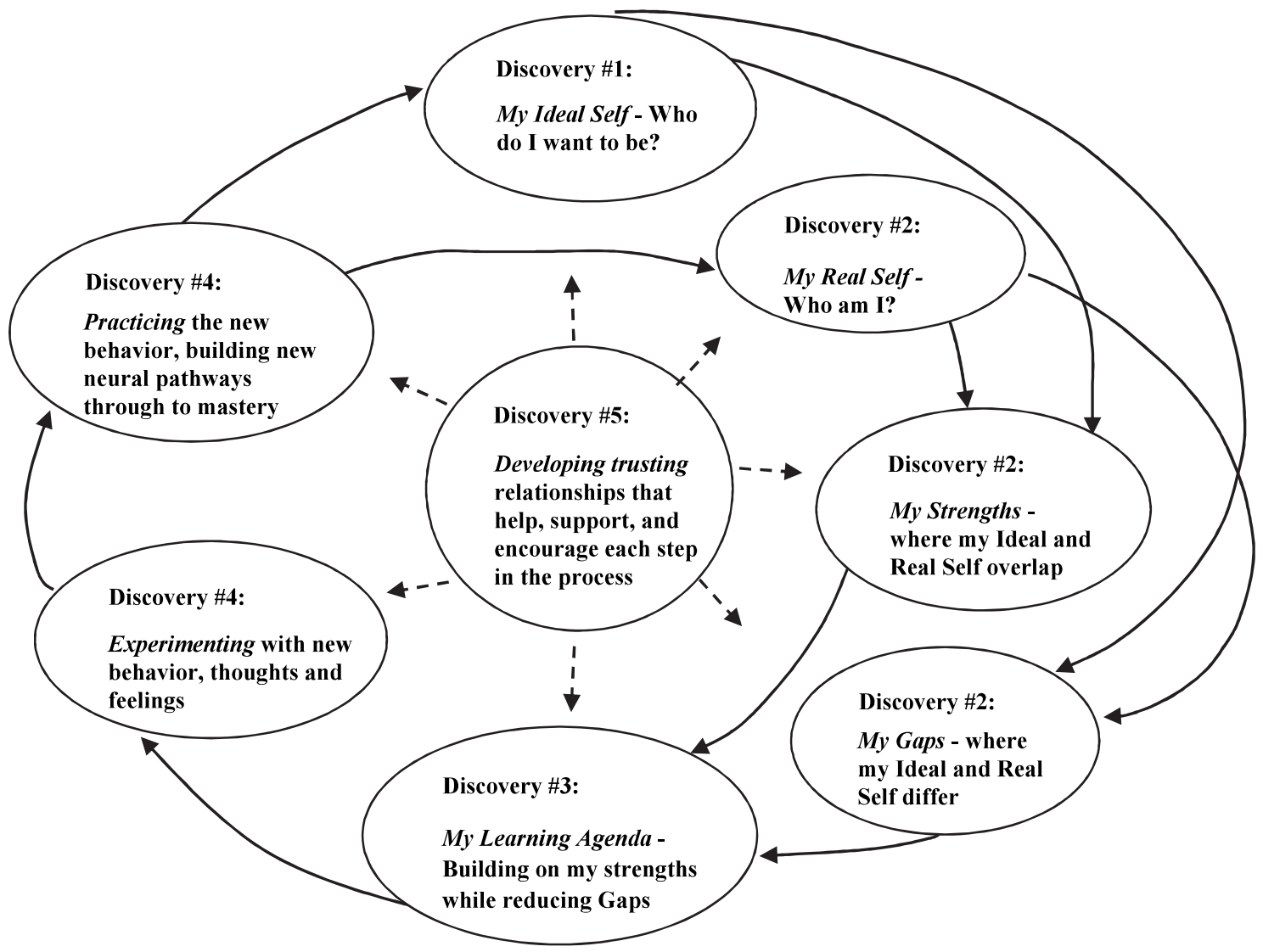

The onset of a disease can be an opportunity or "wake-up" call to rethink one's life purpose and to put into meaningful context a person's potential capacities as they relate to the ideal self-image. ICT suggests that individuals are more likely to change when they take responsibility for the change and they will do this when it is their ideal to which they are changing. Quite simply, this makes the change meaningful to them. The core of ICT is "intentionally developing or strengthening an aspect of who you are or who you want to be, or both" (Goleman et al., 2002, p. 109).

Moreover, the personal depiction of one's ideal self becomes important for individuals with chronic disease when managing the traditional encounter with a physician/health provider. When a physician tells a patient how that individual should be different, the physician is imparting his or her version of the patient's ideal self. How much of the physician's version of this image matches that of the patient's determines the degree to which it becomes part of the patient's ideal self. The potential for contributing to the patient's ideal self will likewise determine the extent of adherence to other aspects of the patient's treatment regime.

Across the country in the competitive health care marketplace there is a focus on patient-centric approaches to health care service delivery driven by patient-centered results like patient satisfaction and quality of life (Rao et al., 2000). Therefore, optimal management of chronic disease involves appropriate actions by both patients and health providers and collaboration between the two to achieve this goal. Engaging individual volition and emotion is viewed in the learning literature (Boyatzis et al., 1995) as a significant element for successful individual change. However, given the inconsistent success of diabetes education programs (Clement, 1995), for instance, researchers (Wagner et al., 1996) have indicated that these programs have not taken into account the patient's personal desire for change and more efforts 
should be made to do so. As such, centering patients in health care service delivery and in their own intentional change process may lead to more consistently positive patient outcomes.

In particular, Hibbard (2009) notes the difficulty in "activating" a patient or encouraging patients to take action and change their health-related behaviors given that "The traditional patient role is to be compliant, passive, and trusting" (p. 3). Such traditional patient behavior is inconsistent with the behavior needed by a patient with a new chronic condition who may have to learn new skills and knowledge to manage their condition. This new learning can include complicated treatment regimens and monitoring symptoms using various devices to monitor glucose and blood pressure levels for instance (Bodenheimer, Lorig, et al., 2002). In addition, patients with chronic disease are expected to adopt a new lifestyle that better focuses on nutrition, exercise, and medication adherence which are often in conflict with culturally and socially embedded contexts (Hibbard, 2009). Therefore, being able to facilitate ICT's Discovery \#1 of the patient's ideal self would give more meaning and purpose to help engage the patient with the behaviors necessary to achieve better health. Likewise, to improve the effectiveness of workplace wellness programming, focus should be placed on identifying the individual motivators of the ideal self (Dyck \& Lovelace, 2012).

\section{Discovery \#2: The Real Self}

The second Discovery in the ICT model involves the introspective task of discovering one's real self. This is a chance to discover one's real self with a new maturity, sense of awareness, and perspective. The real self is comprised of one's behavior, deeply held values, and strengths where they are in harmony with their ideal self, and gaps, where there is disaccord with the ideal self. The ICT model suggests reconsidering the emphasis placed on one's strengths in the context of aspiring to one's ideal self. The subsequent selection of one's distinctive strengths or those strengths most characteristic of the individual is applied to the Learning Agenda (Discovery \# 3) of the individual seeking his or her ideal self (Dyck, 2017). This focus on strengths is different from what is typically the case, for instance, in more problemcentric organizational change designs analogous to those common in quality improvement initiatives, i.e., focusing on what is "wrong" (Benner \& Tushman, 2003). A shorter, more productive, and more enjoyable journey happens when we focus on those attributes most characteristic of our ideal self, i.e., what is "right" (Seligman, 2008).

In fact, the mechanism to facilitate transformation rests in using the person's strengths. Human strengths can include individual level traits such as optimism, self-efficacy, and resilience (Staudinger \& Pasupathi, 2000) that a person frequently displays. Such capacities can be identified by the individual (the real self) as a self-reflective agent of change (Caprara \& Cervone, 2003) drawn from previous life experiences and by those in his or her community of interest (Tornow et al., 1998). Self-management, patient education, and collaborative care/patient participation comprise the patient's self-care tasks and can inform the individual's real-self.

Relative to chronic disease, individuals undergo assessments to evaluate their risk for obesity, diabetes or cardiovascular disease. For obesity, this determination is based on a metric called the Body Mass Index (BMI) and is calculated using this formula: BMI = (weight (lbs.) X 703)/height (in. $)^{2}$. The World Health Organization (2009) states "A BMI over $25 \mathrm{~kg} / \mathrm{m}^{2}$ is defined as overweight, and a BMI of over $30 \mathrm{~kg} / \mathrm{m}^{2}$ as obese." Waist circumference is the other contemporary measurement tool which identifies men with a waist measurement over 40 inches and women with a waist measurement over 35 inches as obese (American Medical Association, 2003).

Relative to diabetes, insulin is a hormone that is needed to convert sugar, starches and other food into energy needed for daily life. The cause of diabetes continues to be a mystery, although both genetics and environmental factors such as obesity and lack of exercise appear to play roles. Chronic levels of blood glucose can be assessed by measuring the level of glycosylated hemoglobin $\left(\mathrm{HbA}_{1 \mathrm{c}}\right)$, a test which "integrates" glucose levels over time. Control of levels of blood glucose is important; chronically high levels increase the risk for the development of complications affecting the eyes, kidney, and nerves. In fact, lowering $\mathrm{HbA}_{1 \mathrm{c}}$ levels among diabetes patients is a vital concern given that for every $1 \%$ reduction in $\mathrm{HbA}_{1 \mathrm{c}}$ levels the risk of developing microvascular diabetic complications is reduced by an average of 
$40 \%$ (DHHS, 2003). For example, from $8.0 \%$ to $7.0 \%$ where typical normal upper limit for $\mathrm{HbA}_{1 \mathrm{c}}$ is approximately $5.5 \%$ to $6.0 \%$.

In addition, high blood pressure can be an indicator of cardiovascular disease. Blood pressure is the force in the arteries when the heart beats (systolic pressure) and when the heart is at rest (diastolic pressure). It is measured in millimeters of mercury ( $\mathrm{mm} \mathrm{Hg}$ ). High blood pressure (or hypertension) is defined in an adult as a blood pressure greater than or equal to $140 \mathrm{~mm} \mathrm{Hg}$ systolic pressure or greater than or equal to $90 \mathrm{~mm} \mathrm{Hg}$ diastolic pressure (CDC, 2017). Determining the real self as related to chronic disease requires assessment from a health professional. However, once this information is acquired, ICT posits that personal change and learning results from reconciling the discontinuity occurring between the ideal self (who you want to be) and the real self (who you are) by using one's strengths to facilitate the transition.

\section{Discovery \#3: The Learning Agenda}

Closely following the awareness of the real self comes the development of the individual's learning agenda. Setting goals and making plans to achieve them have long been a part of self-directed change theories (Kolb \& Boyatzis, 1970a). Researchers (Locke \& Latham, 1990) have concluded that setting goals does compel action toward their completion especially so if the goals are clearly defined and challenging. Leonard (1996) confirms this finding and adds that targeting, remembering, and remaining highly committed to a goal results in significant behavioral change. Finally, Wheeler (1999) found that intentional change initiatives are enhanced when individuals are able to work on learning goals in multiple life spheres, with multiple relationships, and with multiple activities. Building on this research, Discovery \#3 of the ICT model represents the pathway for reaching the ideal self by using and building upon one's strengths and reducing gaps.

For individuals managing chronic disease, management of diet, exercise, and medication, as well as self-monitoring to self-correct behaviors where needed encompass the self-management activities and informs the individual's learning agenda. For patients with diabetes, for instance, self-management is particularly important as patients and their families provide $95 \%$ of the patients' care (Bartlett, 1986; de Weerdt et al., 1989b). Improved outcomes, increased patient satisfaction, and greater adherence to treatment regimens are associated with active patient participation in the self-management of their disease (Anderson, 1993).

Unfortunately, patients' behavioral change from self-management training programs alone is inconsistent (Cook et al., 2001; Cook et al., 1999; Norris et al., 2001; Norris et al., 2002). For example, Bodenheimer and colleagues (2002) found that 11 out of 23 asthma self-management programs showed decreases in symptoms with 8 of 15 asthma self-management programs resulting in reduced emergency room (ER) visits. Further, for patients enrolled in a self-management program, improvements in health status, health behaviors, and self-efficacy along with fewer ER visits were reported by Lorig and Fries (2000). As such, while self-management programs can be effective, integrating the intentionality and holistic approach of ICT can improve outcomes in the change process.

\section{Discovery \#4: Experimenting and Practicing New Behaviors}

Discovery \#4 involves experimenting with new behaviors, thoughts, and feelings. It also requires practicing newly planned behaviors to the point of mastery so that old habits are broken and new neural pathways are strengthened (Bennett-Goleman, 2001). For patients with chronic disease, this means trying out new self-management practices such as diet and exercise changes in the context of their self-ascribed ideal self. However, the focus of their learning goals is not on the change itself. Instead, the emphasis is on how they can move closer to their preferred future by enacting their learning goals. Research (Rhee, 1997) supports the contention that it is important to find suitable opportunities in contexts of one's daily life so that experimentation and practice can occur with new behaviors.

Moreover, individuals need to be involved and partners in their care management to increase their adherence to the new lifestyle behaviors (Lorig et al., 2000). For example, interventions that increase patient participation are effective for improving glycemic control, perceived health status, and functioning 
(Greenfield et al., 1995). Similarly, increasing the involvement of patients in decision making during hospitalization resulted in increased functional status and metabolic control (Rost et al., 1991). Indeed, patient participation studies stress the central need to find ways to increase patient participation in their own care to create important behavioral changes. Integrating incentives for participating in wellness programming and applying the ICT model to managing and reducing chronic disease can offer new hope for managing this epidemic.

\section{Discovery \#5: Trusting Relationships}

The fifth Discovery is to develop trusting relationships that help, support, and encourage each step in the ICT process. This Discovery may occur at any point in the journey. It suggests that one really develops in the context of others. It is while one is in relationships where one discovers his or her strengths and gaps and when one can best craft a learning agenda. Others in one's circle of influence can best help to raise the level of self-awareness for the person invoking the ICT process. It is in these reference groups that one can get feedback, affirmation, and information to monitor progress on his or her goals provided that sufficient psychological safety (Edmondson, 1999) exists to enable one's fullest contribution. Research indicates that these types of interpersonal connections can leave a positive imprint on individuals that is enduring and meaningful to their growth and development (Dutton \& Heaphy, 2003).

In summary, ICT is an individual change process grounded in the intentionality of the individual seeking change motivated by his or her own epiphany for the need to change. The five Discoveries outlined describe how this change process proceeds and works at each step. Depending upon the individual change envisioned, it may take several iterations of this process to fully achieve one's ideal self. In the next section, we review studies where ICT has been applied to health care contexts.

\section{INTENTIONAL CHANGE THEORY IN HEALTH CARE}

ICT has been often applied to leadership development (Boyatzis et al., 2015; Boyatzis et al., 2013). However, research is emerging that examines ICT within health care contexts. These studies include two outcome studies conducted in health care settings concerning sobriety (Boyatzis, 1976; Cutter et al., 1977), an intervention study using ICT to compare it against the traditional model for diabetes patient education, (Dyck et al., 2006), a study that applies ICT to physician/patient communication in a clinical diagnostic encounter (Dyck, in press), and a study using ICT to examine patient treatment adherence (Khawaja, 2011).

The prior health care studies (Boyatzis, 1976; Cutter et al., 1977) using ICT that concerned alcohol sobriety demonstrated improved social rehabilitation (i.e. sobriety maintenance and work sustainability) for the treatment group. In Boyatzis' (1976) study the sample was comprised of older (mean age 52 years) and primarily male (98 men and 2 women) alcoholics most of whom (84\%) had prior treatment and a long history of alcoholism. Creating much greater self-awareness and long-range personal goal-setting were unique aspects of the intervention compared to standard treatment for alcoholism.

A study at a Veterans Affairs Medical Center with diabetes patients evaluated a patient-centered intervention based on ICT to improve diabetes care against the traditional model for diabetes patient education (Dyck et al., 2006). The aims of the study were to compare the ICT-based intervention to usual diabetes education and see the impact on diabetes outcomes concerning self-management learning, selfcare, and clinical improvements. Preliminary conclusions from the intervention found "Participants fundamentally engaged with concepts of dreams, values, and visions" and there was an "Overall, positive reception to "ideal self" work/exercises as first step in change process" (Caron et al., 2005, p. 16).

In another study using ICT concepts, Dyck (in press) asked the question: "Does a medical student's overall positive versus negative emotional tone influence his or her effectiveness in a clinical diagnostic encounter with a standardized patient?" The study analyzed 116 videotaped encounters between medical students from a medical school in a major mid-western university and standardized patients who were trained and provided with scripts to participate in the study. Dyck (in press) found that by applying ICT to 
the physician-patient encounter, physicians could be more effective through the positive emotional tone that they established with their patients.

Finally, Khawaja (2011) also applied ICT concepts in physician-patient encounters with patients who had type 2 diabetes. Patients' emotional state as facilitated with ICT was found to "completely mediate the relationships of empathy, trust, rapport and diabetes knowledge with treatment adherence" (Khawaja, 2011: 15). Taken together, these studies demonstrate the early potential for larger scale application of ICT to the chronic disease context.

\section{EXISTING HEALTH BEHAVIOR CHANGE MODELS AND INTENTIONAL CHANGE THEORY}

As noted in the introduction, five models of health behavior change are commonly cited in the literature: Transtheoretical Model (Prochaska \& DiClemente, 1982), Theory of Reasoned Action (Ajzen \& Fishbein, 1980; Fishbein \& Ajzen, 1975) and Theory of Planned Behavior (Ajzen \& Fishbein, 1980; Fishbein \& Ajzen, 1975), Critical Care Model (Wagner, 1998), and the Health Belief Model (Rosenstock, 1974). As outlined in Table 1, these theories compete with, support, or have comparable elements to ICT. We briefly describe these models and then analyze how each of them relates to ICT.

\section{TABLE 1}

EXISTING THEORIES OF HOW INDIVIDUAL FACTORS AFFECT HEALTH BEHAVIOR CHOICES RELATIVE TO ICT

\begin{tabular}{|c|c|c|c|}
\hline $\begin{array}{l}\text { Existing Theoretical } \\
\text { Model }\end{array}$ & $\begin{array}{l}\text { Relationship to } \\
\text { ICT }\end{array}$ & $\begin{array}{l}\text { Focus of Existing } \\
\text { Theoretical Model }\end{array}$ & $\begin{array}{l}\text { Key Concepts of Existing Theoretical } \\
\text { Model }\end{array}$ \\
\hline $\begin{array}{l}\text { Transtheoretical } \\
\text { Model (Jones et al., } \\
\text { 2003) }\end{array}$ & Competing & Readiness to change & $\begin{array}{l}\text { Precontemplation } \\
\text { Contemplation } \\
\text { Preparation } \\
\text { Action } \\
\text { Maintenance } \\
\text { Relapse }\end{array}$ \\
\hline $\begin{array}{l}\text { Theory of Reasoned } \\
\text { Action/ Theory of } \\
\text { Planned Behavior } \\
\text { (Ajzen, 1991) }\end{array}$ & Supporting & $\begin{array}{l}\text { Conditions } \\
\text { antecedent to } \\
\text { intention }\end{array}$ & $\begin{array}{l}\text { Behavioral intention } \\
\text { Subjective norms } \\
\text { Attitudes } \\
\text { Perceived behavioral control }\end{array}$ \\
\hline $\begin{array}{l}\text { Chronic Care Model } \\
\text { (Wagner, 1998) }\end{array}$ & $\begin{array}{l}\text { Comparable } \\
\text { Elements }\end{array}$ & $\begin{array}{l}\text { Informed and } \\
\text { activated patient } \\
\text { collaboration with } \\
\text { prepared, proactive, } \\
\text { practice team }\end{array}$ & $\begin{array}{l}\text { Community } \\
\text { Health system } \\
\text { Self-management support } \\
\text { Delivery system design } \\
\text { Decision support } \\
\text { Clinical information systems }\end{array}$ \\
\hline $\begin{array}{l}\text { Health Belief Model } \\
\text { (Rosenstock, 1974) }\end{array}$ & $\begin{array}{l}\text { Comparable } \\
\text { Elements }\end{array}$ & $\begin{array}{l}\text { Health problem } \\
\text { threat perception }\end{array}$ & $\begin{array}{l}\text { Perceived susceptibility } \\
\text { Perceived severity } \\
\text { Perceived benefits of action } \\
\text { Perceived barriers to action } \\
\text { Cues to action } \\
\text { Self-efficacy }\end{array}$ \\
\hline
\end{tabular}

\section{Competing - Transtheoretical Model}

This model of health behavior change contends that individuals go through five stages that define behavior change: Pre-contemplation; Contemplation; Preparation; Action, and Maintenance. Actual 
change is influenced by past behaviors and the individual's intentions for future actions. It is not uncommon for individuals to move back and forth among the stages, for example, relapsing from maintenance to contemplation. The Transtheoretical Model is currently popular in diabetes research (Arafat et al., 2016).

Relating this model to ICT, we assert that the stage of change assessment is subsumed in the ICT model. Specifically, the pre-action stages of pre-contemplation, contemplation, and preparation in the Transtheoretical Model parallel ICT's first three Discoveries and the action and maintenance stages of Transtheoretical model are similar to ICT's experimentation and practice Discoveries as discussed in related research (Wheeler, 1999). Of significance, the Transtheoretical model is a "readiness for change" model whereas ICT is a "want to change" model (Peyrot, 2001).

The distinction is important as just being ready for change may not be enough to sustain the motivation for change. The change for which the individual is ready may not be the change that he or she personally desires, which will impact the implementation of the change and the likelihood of its continuance. While the Transtheoretical Model is able to categorize the stage that a person currently occupies, it only provides problem-centric experiential and behavioral processes to explain the change or to help facilitate someone's transition between stages (Velicer et al., 1998). In contrast, ICT goes beyond Transtheoretical Model's deficit-attending processes such as "dramatic relief" and "stimulus control" to catalyze individuals to change that which is of greatest import to them in the context of their future lives.

\section{Supporting - Theory of Reasoned Action and Theory of Planned Behavior}

The Theory of Reasoned Action states that the probability of an individual engaging in health behavior change is related to the individual's belief or attitude towards the preventative behavior and the social influences of engaging or not engaging in the behavior. The Theory of Planned Behavior adds to this model by including the degree to which the individual views the behavior change as within their control. The Theory of Reasoned Action and the Theory of Planned Behavior support ICT and the positive role of intentionality in personal change by suggesting perceived behavioral control; attitude toward the behavior; and subjective norm as three independent antecedent determinants of intention.

The Theory of Planned Behavior is a refinement of Theory of Reasoned Action (Ajzen \& Fishbein, 1980; Fishbein \& Ajzen, 1975) by including behaviors over which people do not have complete volitional control. This is referred to as perceived behavioral control in the Theory of Planned Behavior (Ajzen, 1991) and perhaps more readily identified as consistent with the conceptualization of self-efficacy (Bandura, 1977, 1982) or one's assessment of how well one can perform the behavior. Attitude toward the behavior refers to the extent to which a person has a favorable or unfavorable assessment of the behavior. Finally, subjective norm refers to the perceived social pressure of whether to perform the behavior. Although the relative importance of these three factors vary across behaviors and applications, it is generally believed that the more favorable the attitude and subjective norm, and the greater the perceived behavioral control (self-efficacy), the stronger will be the person's intention to perform the behavior (Ajzen, 1991). Research (Rise et al., 2003) suggests that the Theory of Planned Behavior may benefit by including the concept of intention into its model to provide a more complete understanding of behavior change.

Therefore, the Theory of Reasoned Action and the Theory of Planned Behavior support ICT as an individual's intention or purpose for change is at the core of ICT. As noted in our earlier discussion of ICT, individuals move and take action in the direction which best serves their ideal self. While help is needed from one's trusting relationships as noted in ICT's Discovery \# 5, the change process does not begin until an individual's meaningful purpose in the form of one's ideal self is identified.

\section{Comparable Elements - Chronic Care Model and Health Belief Model}

Intentional Change Theory reflects elements and assumptions of the Chronic Care Model (Wagner, 1998) and the Health Belief Model (Rosenstock, 1974). Both models have been long-used for forecasting the health behavior choices of patients. Both the Chronic Care Model and the Health Belief Model are cited widely in the health promotion literature (Lee et al., 2018; Yeoh et al., 2018). Although CCM's 
emphasis is on the process between patient and the practice team, the individual features of this model are included in the comparison.

Wagner and colleagues $(1996 ; 2001)$ developed the Chronic Care Model in response to patient concerns of insufficient care, physician participation, and synchronization among care givers (Kadu \& Stolee, 2015). The Chronic Care Model was intended to resolve these concerns and link evidence-based chronic disease care with physician practices (Kadu \& Stolee, 2015). According to Bodenheimer and colleagues (2002), the care for chronic disease patients occurs within three "overlapping galaxies" including the public and private community at large, health care system, and provider organization. The Chronic Care Model specifies six elements within this "trigalactic universe:" community resources and policies, health care organization, self-management support, delivery system design, decision support, and clinical information systems (Bodenheimer, Wagner, et al., 2002).

Taken together, the universe within which the Chronic Care Model is applied implies an integration with the patient's preferred care as evidenced in ICT's Discoveries. The Chronic Care Model states that improvement in patient outcomes are derived from effective interactions between an "informed, activated patient" and a "prepared, proactive practice team" (Bodenheimer, Wagner, et al., 2002) which is comparable to ICT's Discovery \# 5, trusting relationships. Further, the Chronic Care Model's (Wagner et al., 1996) activated patient element is also mirrored in ICT specifically in Discovery \# 1 , the ideal self, when individuals articulate their preferred futures.

The Health Belief Model is considered a commonsense model that combines the individual's perceived susceptibility to the disease, the perceived severity of the disease, and the perceived benefits and barriers of the treatment. These aspects of the model compare to ICT's Discovery \# 2, the Real Self wherein one's strengths and weaknesses are considered in the change process. Also factored into the Health Belief Model are cues to action, such as advice from friends and family, media health campaigns that influence the likelihood that the individual will change their behavior. This part of the Health Belief Model compares to ICT's Discovery \# 5, the development of trusting relationships.

The Health Belief Model's (Janz \& Becker, 1984) self-efficacy element is reflected in ICT's Discovery \# 2, the real self, particularly when individuals recognize that there are strengths they believe they possess and utilize them to reduce the gaps between their real and ideal selves. An underlying assumption of the Health Belief Model is that the preventative health behavior requested of the individual must be intrinsically rewarding to that person (Carpenter, 2010). This assumption compares favorably with ICT's assertion that one's ideal self is the primary driver of individual change.

In summary, the Transtheoretical Model competes with ICT and offers different perspectives on individual change. The Theory of Reasoned Action and Theory of Planned Behavior support ICT and the role of intentionality in personal change. The Chronic Care Model and the Health Belief Model have some elements that are comparable to ICT. The compatibility of ICT with other theories in use enhances its likelihood of adoption by individuals implementing health behavior change interventions (Rogers, 1995). In addition, ICT extends other parts of these theories by including missing components that researchers have found desirable. Finally, as discussed next, the results from these theories indicate that they have room for improvement.

\section{DISCUSSION AND CONCLUSION}

Nothing is as practical as good theory (Van de Ven, 1989) and there is "nothing as practical as finding the right theory for the prevention need that has been identified" (Crosby \& Noar, 2010, p. 259). Health behavior change programs informed by theory are more effective in changing behavior than programs not informed by theory (Noar \& Zimmerman, 2005). However, the development of health behavior change theory has not kept pace with the practice of health behavior change programs (Crosby \& Noar, 2010). Only about one third of published health behavior research uses theory (Painter et al., 2008). The most prominently used existing theories of health behavior change discussed in this paper have been used almost exclusively for more than the last two decades (Glanz \& Bishop, 2010; Noar \& Mehrotra, 2011). 
The consistent use of these theories over the decades is impressive. Yet, the effectiveness of these theories is less impressive, and researchers are calling for significant modification to the theories and even abandonment of them. For instance, some researchers (Davis et al., 2015) believe that social economic status is an important contextual factor omitted from much of the health behavior change theories. Carpenter (2010), after completing a meta-analysis of the effectiveness of the Health Belief Model for predicting behavior recommends the discontinuance of its use. Sniehotta and colleagues (2014) similarly believe it is "Time to retire the Theory of Planned Behaviour" (p. 1) given the heavy criticism it has received and limited predictive validity. Baptista et al. (2016) determined that using single elements from the Chronic Care Model in interventions are insufficient for clinical outcome improvement and instead recommended that interventions unite all of the Chronic Care Model' six elements. However, in the subsequent and recent review by Reynolds and colleagues (2018), improvements in outcomes in such studies were not significant when compared with studies of interventions using fewer elements. We propose that ICT can offer a practical solution to workplace wellness programming (Dyck \& Lovelace, 2012) given its strong theoretical foundations and promising applications to health behavior change.

In conclusion, this paper set out to examine the potential of using ICT to improve the condition of patients with chronic disease. In so doing, we reviewed the ICT model and highlighted five existing theories of individual health behavior change and their respective relationships to ICT in the context of chronic disease. To maintain the robustness and relevance of existing theories as well as to advance new theoretical developments, these theories need to be tested, compared to each other, and revised (Painter et al., 2008). Given the criticisms of the existing theories, ICT could offer a meaningful alternative to patients with chronic disease who make a deliberate and voluntary choice to move toward their ideal self.

\section{REFERENCES}

Ajzen, I. (1991). The theory of planned behavior. Organizational Behavior and Human Decision Processes, 50, 179-211. doi: 10.1016/0749-5978(91)90020-T

Ajzen, I., \& Fishbein, M. (1980). Understanding attitudes and predicting social behavior. Englewood Cliffs, NJ: Prentice Hall.

American Medical Association. (2003). Assessment and management of adult obesity: A primer for physicians, 2(23). Atlanta, GA: Robert Wood Johnson Foundation.

Anderson, R. M. (1993). Educational principles and strategies. In V. Peragallo-Dittko \& K. Meyer (Eds.), A core curriculum for diabetes education. Chicago, IL: The American Association of Diabetes Educators.

Arafat, Y., Ibrahim, M., Izham, M., \& Awaisu, A. (2016). Using the transtheoretical model to enhance self-management activities in patients with type 2 diabetes: A systematic review. Journal of Pharmaceutical Health Services Research, 7(3), 149-156.

Bandura, A. (1977). Self-efficacy: Toward a unifying theory of behavioral change. Psychological Review, 84(2), 191-215. doi: 10.1016/0146-6402(78)90009-7

Bandura, A. (1982). Self-efficacy mechanism in human agency. American Psychologist, 37(2), 122-147. doi: 10.1037/0003-066X.37.2.122

Baptista, D. R., Wiens, A., Pontarolo, R., Regis, L., Reis, W. C. T., \& Correr, C. J. (2016). The chronic care model for type 2 diabetes: A systematic review. Diabetology \& Metabolic Syndrome, 8(1), 7. doi: 10.1186/s13098-015-0119-z

Bartlett, E. (1986). Historical glimpses of patient education in the United States. Patient Education and Counseling, 8(2), 135-149. doi: 10.1016/0738-3991(86)90085-6

Benner, M. J., \& Tushman, M. L. (2003). Exploitation, exploration, and process management: The productivity dilemma revisited. Academy of Management Review, 28(2), 238-256.

Bennett-Goleman, T. (2001). Emotional alchemy: How the mind can heal the heart. New York: Harmony Books.

Bodenheimer, T., Lorig, K., Holman, H., \& Grumbach, K. (2002). Patient self-management of chronic disease in primary care. JAMA, 288(19), 2469-2475. 
Bodenheimer, T., Wagner, E. H., \& Grumbach, K. (2002). Improving primary care for patients with chronic illness. JAMA, 288(14), 1775-1779.

Boyatzis, R., Rochford, K., \& Taylor, S. (2015). The role of the positive and negative emotional attractors in vision and shared vision: Toward effective leadership, relationships and engagement. Frontiers in Psychology, 6, 217.

Boyatzis, R. E. (1976). Power motivation training: A new treatment modality. In F. Seixas \& S. Eggleston (Eds.), Annals of the New York Academy of Sciences, 273, 525-532.

Boyatzis, R. E. (1999). Self-directed change and learning as a necessary meta-competency for success and effectiveness in the twenty-first century. Keys to employee success in coming decades, 15-31. Westport, CT: Quorum Books.

Boyatzis, R. E. (2001). How and why individuals are able to develop emotional intelligence. In C. Cherniss \& D. Goleman (Eds.), The emotionally intelligent workplace, 234-253. San Francisco, CA: Jossey-Bass.

Boyatzis, R. E., Cowen, S. S., \& Kolb, D. A. (1995). Innovation in professional education: Steps on a journey from teaching to learning. San Francisco, CA: Jossey-Bass.

Boyatzis, R. E., \& Kolb, D. A. (1969). Feedback and self-directed behavior change. (Working Paper), MIT, Cambridge, MA.

Boyatzis, R. E., \& McLeod, P. L. (2001). The guest editors' corner: Our educational bottom line: Developing the whole person. Journal of Management Education, 25(2), 118-123.

Boyatzis, R. E., Smith, M. L., Van Oosten, E., \& Woolford, L. (2013). Developing resonant leaders through emotional intelligence, vision and coaching. Organizational Dynamics, 42(1), 17-24. doi: http://dx.doi.org/10.1016/j.orgdyn.2012.12.003

Buttorff, C., Ruder, T., \& Bauman, M. (2017). Multiple chronic conditions in the United States. Rand Corporation.

Caprara, V. G., \& Cervone, D. (2003). A conception of personality for a psychology of human strengths: Personality as an agentic, self-regulating system. In L. G. Aspinwall \& U. M. Staudinger (Eds.), A psychology of human strengths: Fundamental questions and future directions for a positive psychology, pp. 61-74. Washington, DC: American Psychological Association.

Carnethon, M., Whitsel, L. P., Franklin, B. A., Kris-Etherton, P., Milani, R., Pratt, C. A., . . Metabolism. (2009). Worksite wellness programs for cardiovascular disease prevention: A policy statement from the American Heart Association. Circulation, 120(17), 1725-1741. doi: 10.1161/circulationaha.109.192653

Caron, A., Aron, D., Dyck, L. R., Watts, S., Davidson, M., \& Boyatzis, R. E. (2005). Intentional Change Theory Study Update - VA HSR\&D \& NIH Grant Proposals. Paper presented at the Works-inProgress, Veterans Affairs Medical Center, Cleveland, OH.

Carpenter, C. J. (2010). A meta-analysis of the effectiveness of health belief model variables in predicting behavior. Health Communication, 25(8), 661-669. doi: 10.1080/10410236.2010.521906

Carr, A. (2004). Positive psychology: The science of happiness and human strengths. Hove, East Sussex: Brunner-Routledge.

CDC. (2014). National Diabetes Statistics Report, 2014.

CDC. (2017). National Diabetes Statistics Report, 2017.

Clement, S. (1995). Diabetes self-management education. Diabetes Care, 18(8), 1204-1214.

Cook, C. B., Lyles, R. H., \& El-Kebbi, I. (2001). The potentially poor response to outpatient diabetes care in urban African Americans. Diabetes Care, 24(2), 209-215.

Cook, C. B., Ziemer, D. C., \& El-Kebbi, I. (1999). Diabetes in urban African Americans: Overcoming clinical inertia improves glycemic control in patients with type 2 diabetes. Diabetes Care, 22(9), 1494-1500.

Crosby, R., \& Noar, S. M. (2010). Theory development in health promotion: Are we there yet? Journal Of Behavioral Medicine, 33(4), 259-263. doi: 10.1007/s10865-010-9260-1 
Cutter, H. S., Boyatzis, R. E., \& Clancy, D. D. (1977). Effectiveness of power motivation training in rehabilitating alcoholics. Journal of Studies on Alcohol, 38(1), 131-141. doi: http://dx.doi.org/10.15288/jsa.1977.38.131

Davis, R., Campbell, R., Hildon, Z., Hobbs, L., \& Michie, S. (2015). Theories of behaviour and behaviour change across the social and behavioural sciences: a scoping review. Health Psychology Review, 9(3), 323-344. doi: 10.1080/17437199.2014.941722

de Weerdt, I., Visser, A., \& van der Veen, E. (1989a). Attitude theories and diabetes education programmes. Patient Education and Counseling, 8, 3-19.

de Weerdt, I., Visser, A. P., \& van der Veen, E. A. (1989b). Attitude behaviour theories and diabetes education programmes. Patient Education and Counseling, 14(1), 3-19.

DHHS. (2003). National diabetes fact sheet. Retrieved March 29, 2004, 2004, from WWW.cdc.gov/diabetes/pubs/factsheet.htm

Dutton, J. E., \& Heaphy, E. D. (2003). The power of high-quality connections. In K. S. Cameron, J. E. Dutton \& R. E. Quinn (Eds.), Positive organizational scholarship, 263-278. San Francisco, CA: Berrett-Koehler Publishers, Inc.

Dyck, L. R. (2017). Coaching with distinctive human strengths for intentional change. Journal of Leadership, Accountability and Ethics, 14(2), 43-55.

Dyck, L. R. (in press). The impact of resonance and dissonance on effective physician-patient communication. In L. Petitta, C. E. J. Härtel, N. M. Ashkanasy \& W. J. Zerbe (Eds.), Research on emotion in organizations: Individual, relational, and contextual dynamics of emotions, 14. Bingley, UK: Emerald Group Publishing.

Dyck, L. R., Caron, A., \& Aron, D. (2006). Working on the positive emotional attractor through training in health care. Journal of Management Development, 25(7), 671-688. doi: $10.1108 / 02621710610678481$

Dyck, L. R., \& Lovelace, K. J. (2012). Finding a fit with fitness: Applying intentional change theory in worksite health promotion programming. Journal of Workplace Behavioral Health, 27(1), 12-31. doi: 10.1080/15555240.2012.640577

Edmondson, A. (1999). Psychological safety and learning behavior in work teams. Administrative Science Quarterly, 44(2), 350-383.

Fishbein, M., \& Ajzen, I. (1975). Belief, attitude, intention, and behavior: An introduction to theory and research. Reading, MA: Wesley.

Flegal, K. M., Kruszon-Moran, D., Carroll, M. D., Fryar, C. D., \& Ogden, C. L. (2016). Trends in Obesity Among Adults in the United States, 2005 to 2014. JAMA, 315(21), 2284-2291.

Glanz, K., \& Bishop, D. B. (2010). The role of behavioral science theory in development and implementation of public health interventions. Annual review of public health, 31, 399-418.

Goetzel, R. Z., \& Ozminkowski, R. J. (2008). The health and cost benefits of work site health-promotion programs. Annual review of public health, 29(1), 303-323. doi:

10.1146/annurev.publhealth.29.020907.090930

Goleman, D., Boyatzis, R. E., \& McKee, A. (2002). Primal leadership: Realizing the power of emotional intelligence. Boston, MA: Harvard Business School Press.

Greenfield, S., Rogers, W., Mangotich, M., Carney, M. F., \& Tarlov, A. (1995). Outcomes of patients with hypertension and non-insulin-dependent diabetes mellitus treated by different systems and specialties: Results from the medical outcomes study. $J A M A, 274(18), 1436-1444$.

Hibbard, J. H. (2009). Using systematic measurement to target consumer activation strategies. Medical Care Research and Review, 66(1 suppl), 9S-27S.

James, W. (1890/1950). The principles of psychology (Vol. two). New York: Dover Publications, Inc.

Janz, N. K., \& Becker, M. H. (1984). The health belief model: A decade later. Health Education Quarterly, 11(1), 1-47.

Jones, H., Edwards, L., Vallis, T. M., Ruggiero, L., Rossi, S. R., Rossi, J. S., . . Zinman, B. (2003). Changes in diabetes self-care behaviors make a difference in glycemic control: The diabetes stages of change (DiSC) study. Diabetes Care, 26(3), 732-737. 
Kadu, M. K., \& Stolee, P. (2015). Facilitators and barriers of implementing the chronic care model in primary care: A systematic review. BMC Family Practice, 16(1).

Khawaja, M. (2011). The mediating role of positive and negative emotional attractors between psychosocial variables and treatment adherence in type II diabetics. ((Unpublished doctoral dissertation).), Case Western Reserve University, Cleveland, OH.

Kolb, D. A. (1971). A cybernetic model of human change and growth. (Working Paper), MIT, Cambridge, MA.

Kolb, D. A., \& Boyatzis, R. E. (1970a). Goal-setting and self-directed behavior change. Human Relations, 23(5), 439-457.

Kolb, D. A., \& Boyatzis, R. E. (1970b). On the dynamics of the helping relationship. Journal of Applied Behavioral Science, 6(3), 267-289.

Kolb, D. A., Winter, S. K., \& Berlew, D. E. (1968). Self-directed change: Two studies. Journal of Applied Behavioral Science, 6(3).

Lee, C. Y., Ting, C. C., Wu, J. H., Lee, K. T., Chen, H. S., \& Chang, Y. Y. (2018). Dental visiting behaviours among primary schoolchildren: Application of the health belief model. International Journal of Dental Hygiene, 16(2), e88-e95. doi: doi:10.1111/idh.12319

Leonard, D. (1996). The impact of learning goals on self-directed change in management development and education ((Doctoral dissertation). Retrieved from ProQuest Dissertations and Theses database. (UMI No. 9723516)).

Locke, E. A., \& Latham, G. P. (1990). A theory of goal setting and task performance. Englewood Cliffs, NJ: Prentice Hall.

Lorig, K., \& Fries, J. (2000). The arthritis helpbook: A tested self-management program for coping with arthritis and fibromyalgia. Cambridge, MA: Perseus Publishing.

Lorig, K., Sobel, D., \& Gonzalez, V. (2000). Living a healthy life with chronic conditions: Selfmanagement of heart disease, arthritis, diabetes, asthma, bronchitis, emphysema and others. Palo Alto, CA: Bull Publishing Company.

Mozaffarian, D., Benjamin, E. J., Go, A. S., Arnett, D. K., Blaha, M. J., Cushman, M., . . Fullerton, H. J. (2016). Executive Summary: Heart Disease and Stroke Statistics-2016 Update: A Report From the American Heart Association. Circulation, 133(4), 447.

Noar, S. M., \& Mehrotra, P. (2011). Toward a new methodological paradigm for testing theories of health behavior and health behavior change. Patient Education and Counseling, 82(3), 468-474. doi: 10.1016/j.pec.2010.11.016

Noar, S. M., \& Zimmerman, R. S. (2005). Health behavior theory and cumulative knowledge regarding health behaviors: are we moving in the right direction? Health Education Research, 20(3), 275290. doi: 10.1093/her/cyg113

Norris, S. L., Engelgau, M. M., \& Venkat Narayan, K. M. (2001). Effectiveness of self-management training in type 2 diabetes: A systematic review of randomized controlled trials. Diabetes Care, 24(3), 561-587.

Norris, S. L., Lau, J., Smith, S. J., Schmid, C. H., \& Engelgau, M. M. (2002). Self-management education for adults with type 2 diabetes: A meta-analysis of the effect on glycemic control. Diabetes Care, 25(7), 1159-1171.

Painter, J. E., Borba, C. P. C., Hynes, M., Mays, D., \& Glanz, K. (2008). The use of theory in health behavior research from 2000 to 2005: A systematic review. Annals of Behavioral Medicine, 35(3), 358-362.

Parks, K. M., \& Steelman, A. (2008). Organizational wellness programs: A meta-analysis. Journal of Occupational Health Psychology, 134(1), 58-68. doi: 10.1037/1076-8998.13.1.58

Peyrot, M. F. (2001). Theory in behavioral diabetes research. Diabetes Care, 24(10), 1703-1705.

Prochaska, J. O., \& DiClemente, C. C. (1982). Transtheoretical therapy: Toward a more integrative model of change. Psychotherapy: Theory, Research \& Practice, 19(3), 276-288. doi: 10.1037/h0088437 
Rao, J. K., Weinberger, M., \& Kroenke, K. (2000). Visit-specific expectations and patient-centered outcomes: A literature review. Archives of Family Medicine, 9(10), 1148-1155. doi: 10.1001/archfami.9.10.1148

Reynolds, R., Dennis, S., Hasan, I., Slewa, J., Chen, W., Tian, D., . . Zwar, N. (2018). A systematic review of chronic disease management interventions in primary care. BMC Family Practice, 19(1), 11-11. doi: 10.1186/s12875-017-0692-3

Rhee, K. (1997). Journey of discovery: A longitudinal study of learning during a graduate professional program (Unpublished doctoral dissertation). Case Western Reserve University, Cleveland, $\mathrm{OH}$.

Rise, J., Thompson, M., \& Verplanken, B. (2003). Measuring implementation intentions in the context of the theory of planned behavior. Scandinavian Journal of Psychology, 44(2), 87-95.

Robbins, R., Norem, J., \& Cheek, J. (1999). Naturalising the self. In L. Pervin \& O. John (Eds.), Handbook of personality: Theory and research. New York: Guilford.

Rogers, E. M. (1995). Diffusion of innovations (4th ed.). New York: The Free Press.

Rosenstock, I. M. (1974). Historical origins of the health belief model. Health Education Monographs, 2(4), 328-335.

Rost, K. M., Flavin, K. S., Cole, K., \& McGill, J. B. (1991). Change in metabolic control and functional status after hospitalization: Impact of patient activation intervention in diabetic patients. Diabetes Care, 14(10), 881-889.

Seligman, M. E. P. (2008). Positive health. Applied Psychology, 57, 3-18. doi: 10.1111/j.14640597.2008.00351.x

Sniehotta, F. F., Presseau, J., \& Araújo-Soares, V. (2014). Time to retire the theory of planned behaviour. Health Psychology Review, 8(1), 1-7. doi: 10.1080/17437199.2013.869710

Staudinger, U. M., \& Pasupathi, M. (2000). Lifespan perspectives on self, personality and social cognition. In T. Salthous \& F. Craik (Eds.), Handbook of cognition and aging (pp. 633-688). Hillsdale, NJ: Erlbaum.

Tornow, W. W., London, M., \& Associates, C. (1998). Maximizing the value of 360-degree feedback: A process for successful individual and organizational development. San Francisco, CA: JosseyBass Inc.

U.S. Centers for Disease Control and Prevention. (2016). Chronic Diseases: The Leading Causes of Death and Disability in the United States. https://www.cdc.gov/chronicdisease/overview/

Van de Ven, A. H. (1989). Nothing is quite so practical as a good theory. Academy of Management Review, 14(4), 486-489. doi: 10.5465/AMR.1989.4308370

Velicer, W. F., Prochaska, J. O., Fava, J. L., Norman, G. J., \& Redding, C. A. (1998). Smoking cessation and stress management: Applications of the transtheoretical model of behavior change. Homeostasis, 38, 216-233.

Wagner, E. H. (1998). Chronic disease management: What will it take to improve care for chronic illness? Effective Clinic Practice, 1(1), 2-4.

Wagner, E. H., Austin, B., \& Von Korff, M. I. (1996). Organizing care for patients with chronic illness. Milbank Quarterly, 74(4), 511-544.

Wagner, E. H., Austin, B. T., Davis, C., Hindmarsh, M., Schaefer, J., \& Bonomi, A. (2001). Improving chronic illness care: Translating evidence into action. Health affairs, 20(6), 64-78.

Wheeler, J. V. (1999). The impact of social environments on self-directed change and learning ((Doctoral dissertation). Retrieved from ProQuest Dissertations and Theses database. (UMI No. 9940173) ).

WHO. (2009). Obesity and overweight: How do we define obesity and overweight? http://www.who.int/dietphysicalactivity/publications/facts/obesity/en/

Yeoh, E. K., Wong, M. C. S., Wong, E. L. Y., Yam, C., Poon, C. M., Chung, R. Y., . . Coats, A. J. S. (2018). Benefits and limitations of implementing Chronic Care Model (CCM) in primary care programs: A systematic review. International Journal of Cardiology, 258, 279-288. doi: https://doi.org/10.1016/j.ijcard.2017.11.057 